\title{
Aspects of climate change induced by human activities: Impact on global natural disaster mortality*
}

\author{
Mark S. Borres ${ }^{1}$ \\ Joel B. Serad ${ }^{2}$ \\ Research Center ${ }^{1}$ \\ University of San Jose-Recoletos \\ Center for Research and Development ${ }^{2}$ \\ University of the Visayas \\ research@uv.edu.ph
}

Submitted: October 1, 2013

Accepted: November 10, 2013

*Topic suggested by Dr. Roberto N. Padua, consultant, USJ-R and UV. Dr. Padua is currently developing the area of Fractal Statistics to support known results in Fractal Geometry.

\begin{abstract}
Some scientists believe that global warming and the consequent climate change are inevitable results of slight deviations of the earth's movement around its axis, a greater majority of scientists stipulate that a greater bulk of the reason for global warming and climate change is accounted for by human activities that destroy the natural environment. The present study looks into the chain of events that lead to natural disasters with specific focus on quantifying the human contribution to these catastrophes. The centroid regression approach identifies the categories of countries that contribute most to the world's $\mathrm{CO} 2$ emissions and determines the relationship among natural resource depletion (\% forest area) and CO2 emission and forest land area. The fitted curve states that the $\mathrm{CO} 2$ emissions increases as the square of the fossil fuel usage by the countries so that those nations, particularly those belonging to the high and very high HDI which are highly developed, contribute tremendously to the level of $\mathrm{CO} 2$ emissions across the globe. The impact of human exploitative activities on the accelerated $\mathrm{CO} 2$ accumulation in the atmosphere led to natural disasters spawned by rising global temperatures increasing natural disaster mortality.
\end{abstract}

Keywords: fossil fuel, renewable energy, $\mathrm{CO}_{2}$ emission, forest area, climate change, global warming, natural disaster mortality

\section{INTRODUCTION}

Scientists believe that global warming threatens the planet in a new and unexpected way as evidenced by triggering earthquakes, tsunamis, avalanches and volcanic eruptions. Reports by international groups of researchers showed that climate change, caused by rising outputs of carbon dioxide from vehicles, factories and power stations, will not only affect the atmosphere and the sea but will alter the geology of the Earth (McGuire, 2009). Recent events in the Philippines have likewise lend credence to these forecasts with the world's strongest super typhoon hitting Central Visayas in the same location still reeling from the havoc created by a magnitude 7.2 earthquake in less than a month's time. While some scientists believe that global warming and the consequent climate change are inevitable results of slight deviations of the earth's movement around its axis, a greater majority 
of scientists stipulate that a greater bulk of the reason for global warming and climate change is accounted for by human activities that destroy the natural environment. The present study looks into the chain of events that lead to natural disasters with specific focus on quantifying the human contribution to these catastrophes.

Van Aalst (2006) opined that human emissions of greenhouse gases are already changing the climate. Several trends in weather extremes are sufficiently clear to inform riskreduction efforts. In many instances, however, the potential increases in extreme events due to climate change come on top of alarming rises in vulnerability. Hence, the additional risks due to climate change should not be analyzed or treated in isolation, but instead integrated into broader efforts to reduce the risk of natural disasters. The emission of greenhouse gases result to rising global temperature (hence, global warming) which in turn precipitate weather extremes. Of all the greenhouse gases, carbon dioxide accounts for the greatest bulk in the earth's atmosphere. Carbon dioxide emissions come from industrial operations, motorized vehicles, factories, and other human activities necessary to support the needs of an ever-growing population. Developed and industrialized nations are the greatest producers of greenhouse gases. In an effort to strike a balance between development and environmental conservation, developed , developing and underdeveloped nations agreed to jointly address the issue of carbon emissions through diplomatic instruments e.g. Kyoto Protocol, Washington Protocol and Rio de Janeiro Protocol, where underdeveloped and developing nations serve as carbon sinks through a "carbon trading" mechanism. These protocols have raised several climate change and environmental ethics issues: how does one account for loss of human lives vis-a-viz continued carbon emission?

Ethical debates emanating from international efforts to curb continued carbon emission will continue with no foreseeable conclusion unless quantitative evidences are presented. This research is an attempt in this direction.

\section{CONCEPTUAL FRAMEWORK}

The major consequences of global warming are the drastic ecological and social changes caused by the rise in global temperatures. There is a scientific consensus that climate change is occurring, and that human activities are the primary driver (Joint Statement of 18 Scientific Organizations 2007). In the northern hemisphere, manifestations of climate changed have surfaced to include, but not limited to, (1) a decrement in the snow cover, (2) sea levels rising inevitably, and (3) considerable increments in the environmental temperature (IPCC, 2007). The Intergovernmental Panel on Climate Change (IPCC) emphasized that the relatively high concentration of greenhouse gas has most likely caused the continually increasing global mean temperatures since mid- $20^{\text {th }}$ century. Moreover, as climate change continues to intensify, global warming also heaps on. Along with this, weather concerns inevitably rise tremendously in terms of frequency and severity. Further, sea level rises on a threatening level. Corollary to these changes, parties to the United Nations Framework Convention on Climate Change (UNFCCC) have agreed to "stabilize greenhouse gas concentrations in the atmosphere at a level that would prevent dangerous anthropogenic interference with the climate system" (UNFCC, 2009).

Observations reveal that there have been changes in weather brought about by climate change. For instance, the type and quantity of rain as well as the intensity and frequency of precipitation have observably changed. Extensive increments in rainfall have taken place, even in places where there was reduction in the total rainfall amounts. With middling level of confidence, IPCC (2012) concluded that occurrences, which brought about heavy rainfall across the globe, were attributed to human causes and influences. In the future, expected changes in rain amounts will bring about a positive shift on the global average. However, there might be a consequent substantial shift as to where and how rain would actually fall. Projections recommend a precipitation in the sub-tropics should decrease, 
and oppositely there will be increments of rainfall in sub-polar latitudes and in selected equatorial regions. This implies that areas which are currently dry on the onset will become even drier while those that are normally wet at present will generally become even wetter. However, this projection may not be true and applicable to every locale, and in some cases can be changed by some local conditions.

Since the 1950s, there is a reduction in the number of cold days and nights all over the world. Some of the changes in the climate were extremes such as floods and tropical cyclones but on a general perspective, these deviations are more difficult to recognize. As previously stated, human factors have relatively led to some of these obvious climate changes.

Resultantly, more very hot days and fewer very cold days associated with the expected climate change can inevitably occur. In most land regions worldwide, there will be a high propensity for heat intensity and frequency to increase. The length of heat waves over these regions could be heightened. The number of cyclones may decrease but if cyclones occur, they would most likely bring a higher maximum wind speed compared to normal ones before. More regions may experience more extreme droughts, including southern Europe and the Mediterranean region, central Europe, central North America, Central America and Mexico, Northwest Brazil, and Southern Africa. Heavier precipitation could greatly bring about an increase of flooding in some localities and even in catchments or regions alike. In regions near water bodies, precipitation will most likely cause to tremendous rising of sea levels.

The effects of tremendous events on the environment and the general public will swerve. Some implications will be favorable e.g., fewer cold extremes will most likely result to lesser number of cold deaths. However generally, the impacts will probably be mostly detrimental to human.

On the other hand, oceans have a very complex function with regards to climate change and global warming. Because they serve as serve as a drop point for carbon dioxide, they take up a considerable amount of the gas that would otherwise be retained in the atmosphere. However, the high levels of carbon dioxide have contributed greatly to ocean acidification. Add to that, with an increase in the oceanic temperature, their function decline and thus lesser $\mathrm{CO} 2$ are absorbed from the environment.

Besides taking in $\mathrm{CO} 2$ from air, oceans also function to absorb excess heat from the atmosphere. Consequently, heat content of oceans has increased significantly and is a lot greater than any other accumulated heat energy in the planet's heat balance on the two time frames (1) 1961 to 2003; and (2) 1993 to 2003. This accounts to greater than $90 \%$ of the prospective increase in the Earth's heat content during these periods.

Global warming is predicted to impact on oceans in a number of ways. Continuing dismal effects can include (1) rising sea levels because of thermal expansion and dissolution of ice sheets and glaciers; (2) increase in the ocean surface temperature, which could result to augmented heat stratification; and (3) extensive disturbances in the ocean flow and movement.

\section{METHODOLOGY}

We made use of data obtained from the data base of the IPCC (2009) readily available from the internet. The variables considered pertained to: the primary energy supply (fossil or renewable), total $\mathrm{CO} 2$ emission, natural resource depletion, impacts (deaths due to natural disaster) across countries with : very high Human Development Index (HDI), high HDI, medium HDI and low HDI.

The relationship between the primary energy supply used by different countries and their corresponding $\mathrm{CO} 2$ emissions was obtained. Fitting a regression curve on these two variables for a given category (say high HDI countries) usually hides the overall global relationship between the two variables. Given this, we estimated the mean energy usage (fossil or renewable) and the mean 
CO2 emissions per category. This method will smooth out the ruggedness that tends to obscure the relationship. The regression curve is fitted that passes through the four (4) centroids.

The centroid regression approach identifies the categories of countries that contribute most to the world's $\mathrm{CO} 2$ emissions. It may be recalled that $\mathrm{CO} 2$ is a primary greenhouse gas that causes rise in global temperature. Global warming, in turn, precipitates extreme weather conditions such as cyclones, hurricanes and typhoons.

The same centroid regression approach was then performed for determining the relationship between natural resource depletion ( $\%$ forest area) and $\mathrm{CO} 2$ emission.

Finally, we estimated the impact of unfettered CO2 emission to the damage brought about by natural disasters to the nations in various categories.

\section{RESULTS AND DISCUSSION}

Table 1 displays the basic statistics obtained for three variables: use of fossil fuel, use of renewable energy sources and $\mathrm{CO} 2$ emissions in megatons across nations in different categories:

Table 1: Basic Statistics for Primary Energy Supply and CO2 Emission by Category

\begin{tabular}{|c|c|c|c|}
\hline HDI Category & Fossil Fuel & $\begin{array}{c}\text { Renewable } \\
\text { Energy }\end{array}$ & $\begin{array}{c}\text { CO2 } \\
\text { emission } \\
(\mathrm{mT})\end{array}$ \\
\hline Very High & $\begin{array}{c}78.31 \\
\text { (sd:18.90) }\end{array}$ & $\begin{array}{c}13.14 \\
\text { (sd:15.82) }\end{array}$ & $\begin{array}{c}150.20 \\
\text { (sd: } 189.8)\end{array}$ \\
\hline High & $\begin{array}{c}83.60 \\
\text { (sd:16.23) }\end{array}$ & $\begin{array}{c}13.80 \\
\text { (sd:15.68) }\end{array}$ & $\begin{array}{c}111.00 \\
\text { (sd:147.0) }\end{array}$ \\
\hline Medium & $\begin{array}{c}69.15 \\
\text { (sd: } 24.98)\end{array}$ & $\begin{array}{c}32.35 \\
\text { (sd:33.22) }\end{array}$ & $\begin{array}{c}72.80 \\
\text { (sd:117.80) }\end{array}$ \\
\hline Low & $\begin{array}{c}30.14 \\
\text { (sd: } 23.51)\end{array}$ & $\begin{array}{c}69.48 \\
\text { (sd: } 23.83 \text { ) }\end{array}$ & $\begin{array}{c}19.52 \\
\text { (sd: } 61.90)\end{array}$ \\
\hline
\end{tabular}

Tabular values show that the standard deviations for the $\mathrm{CO} 2$ emissions are generally larger than their means which indicate a very wide spread in terms of the distribution of $\mathrm{CO} 2$ emissions by the nations per category. That is, various countries found in each category of nations have widely differing $\mathrm{CO} 2$ emissions relative to the average. In fact, this is an indication that the $\mathrm{CO} 2$ emissions can be properly modeled by a fractal distribution (see Padua et al. 2012).

Tabular values likewise indicate that countries belonging to the high and very high Human Development Indices have generally higher $\mathrm{CO} 2$ emissions. In fact, they produce more than double the $\mathrm{CO} 2$ emissions of medium HDI countries. This fact is a reflection of the reality that countries belonging to the high HDI category are highly industrialized and have more cars per capita than the other countries in the lower HDI category.

In contrast, countries belonging to the lower HDI category tend to utilize renewable energy sources. In fact, these countries registered five times bigger utilization of renewable (green) energy sources than those countries that are more economically developed and belonging to the high to very high HDI category.

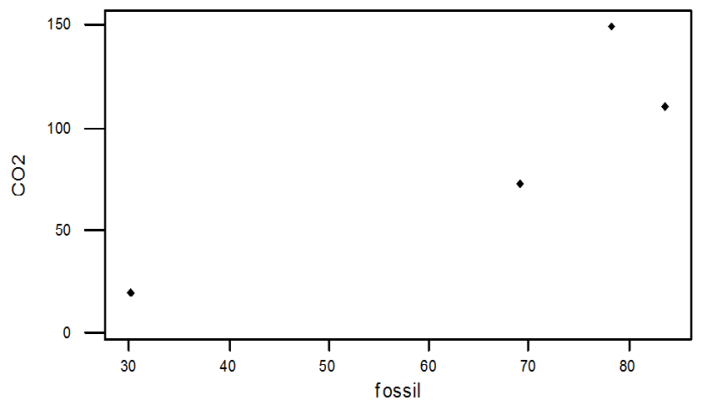

Figure 1. Scatterplot of the centroids of fossil fuel and $\mathrm{CO} 2$ emissions

Figure 1 shows the scatteplot of the centroid of fossil fuel against the centroids of the $\mathrm{CO} 2$ emissions across the different HDI categories. The scatterplot suggests a quadratic curve sloping upwards. The best quadratic function that fits the observations is given below:

The regression equation is CO2 $=1.6+0.0185$ fossil squared 
Table 2. Raw Data for Regression Equation

\begin{tabular}{lllll}
\hline Predictor & Coef & SECoef & T & P \\
\hline Constant & 1.56 & 35.02 & 0.04 & 0.969 \\
Fossils & 0.018462 & 0.006673 & 2.77 & 0.110 \\
S = 31.07 & R-Sq $=79.3 \%$ & R-Sq(adj) & $68.9 \%$ & \\
\hline
\end{tabular}

The fitted curve states that the $\mathrm{CO} 2$ emissions increases as the square of the fossil fuel usage by the countries so that those nations, particularly those belonging to the high and very high HDI which are highly developed, contribute tremendously to the level of $\mathrm{CO} 2$ emissions across the globe. The marginal rate of contribution of fossil fuel utilization to the $\mathrm{CO} 2$ emission can be computed from the derivative: $\mathrm{d}(\mathrm{CO} 2) / \mathrm{d}($ fossil $)=$ $0.037 *$ fossil fuel

This means that for each unit increase in the fossil fuel utilization, approximately $3.7 \%$ of a megaton of $\mathrm{CO} 2$ is added to the global emission (or 37,000 kilos of $\mathrm{CO} 2$ are added).

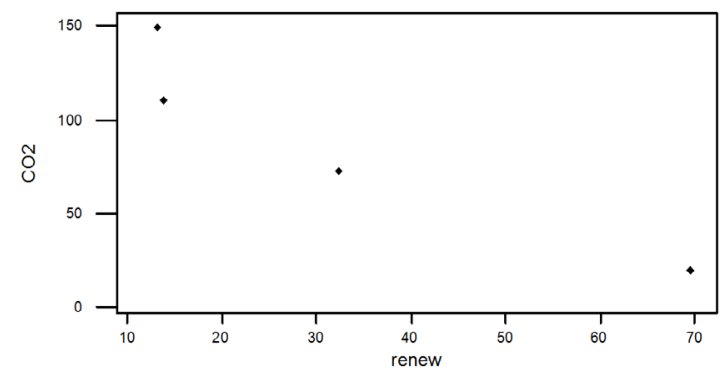

Figure 2. Scatterplot of renewable energy source against CO2 emission

The scatterplot in Figure 2 illustrates downward sloping straight line relationship between the use of renewable energy sources of the nations and their $\mathrm{CO} 2$ emission. The linear regression curve is given below:

The regression equation is $\mathrm{CO} 2=152-1.99$ renew

Table 3. Raw Data for Regression Equation

\begin{tabular}{lllll}
\hline Predictor & Coef & SE Coef & T & P \\
\hline Constant & 152.47 & 19.58 & 7.79 & 0.016 \\
renew & -1.9907 & 0.4959 & -4.01 & 0.057 \\
$\mathrm{~S}=22.68$ & \multicolumn{1}{l}{$\mathrm{R}-\mathrm{Sq}=89.0 \%$} & $\mathrm{R}-\mathrm{Sq}(\mathrm{adj})$ & $83.4 \%$ \\
\hline
\end{tabular}

The use of renewable energy (green energy) appears to drastically reduce $\mathrm{CO} 2$ emission by the countries. In fact, for each

unit of green energy utilization, $\mathrm{CO} 2$ emission is reduced by 1.99 megaton.

Browsing through the green energy utilization of the countries, we find that medium HDI countries and low HDI countries contribute the most to the minimization of carbon emissions across the globe.

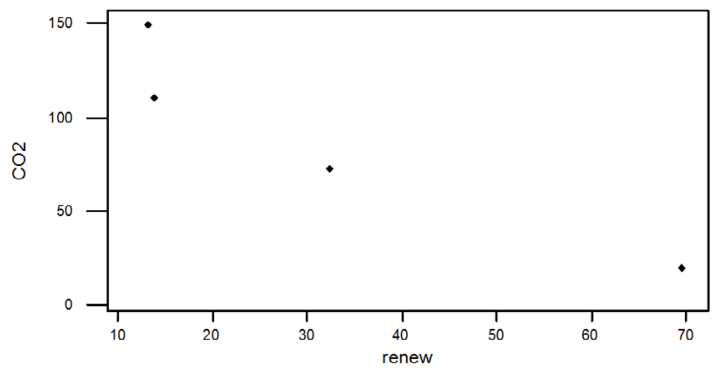

Figure 2. Scatterplot of renewable energy source against $\mathrm{CO} 2$ emission

Table 2. Basic Statistics for Forest Area and Total $\mathrm{CO} 2$ Emission by HDI Category

\begin{tabular}{cccc}
\hline $\begin{array}{c}\text { HDI } \\
\text { Category }\end{array}$ & $\begin{array}{c}\text { Forest Area } \\
\text { (\% of land } \\
\text { area) }\end{array}$ & $\begin{array}{c}\text { Total CO2 } \\
\text { emission } \\
\text { (mT) }\end{array}$ & $\begin{array}{c}\text { Number of deaths } \\
\text { due to natural } \\
\text { disasters } \\
\text { annual average per } \\
\text { million people) }\end{array}$ \\
\hline Very High & $\begin{array}{c}35.05 \\
\text { (sd: } 19.37)\end{array}$ & $\begin{array}{c}150.20 \\
\text { (sd: } 189.8)\end{array}$ & $\begin{array}{c}7.69 \\
\text { (sd: } 11.09)\end{array}$ \\
High & $\begin{array}{c}33.16 \\
\text { (sd: } 20.52)\end{array}$ & $\begin{array}{c}111.00 \\
\text { (sd:147.0) }\end{array}$ & $\begin{array}{c}2.95 \\
\text { (sd: } 8.49)\end{array}$ \\
Medium & $\begin{array}{c}32.53 \\
\text { (sd: } 26.79)\end{array}$ & $\begin{array}{c}72.80 \\
\text { (sd: } 117.80)\end{array}$ & $\begin{array}{c}2.93 \\
\text { (sd: } 3.69)\end{array}$ \\
Low & $\begin{array}{c}28.47 \\
\text { (sd: } 22.88)\end{array}$ & $\begin{array}{c}19.52 \\
\text { (sd: } 61.90)\end{array}$ & $\begin{array}{c}9.78 \\
\text { (sd: 43.93) }\end{array}$ \\
\hline
\end{tabular}

Entries in Table 2 indicate that the forest cover of nations in high to very high HDI categories is generally higher than the forest areas of the countries in the lower categories. All over the world, however, less than half of the forest areas remain intact. The forces of modernization and urbanization encroach into the remaining primary forest covers in several nations; the rate of encroachment is obviously faster in the 
developing and underdeveloped nations as evidenced by smaller percentages of forest areas in the medium and low HDI categories. In contrast, mere developed nations have sophisticated urbanization plans that include a clear resolve to preserve their remaining forested areas.

Countries like the Philippines, with developing economies exploit their forests for logs, timbers and other forest products despite laws and statutes that prohibit logging. In Southern Philippines for instance, vast tracts of forest areas give way to more profitable mining operations. These human exploitative activities are more clearly demonstrated in nations whose economies depend on agriculture, mining, and wood production.

Collectively, all these human exploitative activities result to a surplus of $\mathrm{CO} 2$ because the carbon requirement of plants in both terrestrial and marine environments is exceeded by the rates of carbon emission and forest degradation. Consequently, the accumulation of $\mathrm{CO} 2$ in the atmosphere induces the inevitable "green- house effect" leading to global warming.

Equation (2) shows the relationship between CO2 emission and percentage of forest covers using the centroid regression:

\section{$\mathrm{CO} 2=-542+19.5$ forest cover (2)}

The regression fit is counter-intuitive in the sense that as the percentage of forest covers increases, the rate of $\mathrm{CO} 2$ emissions correspondingly increases. The equation is "actually" describing the phenomenon that as national development intensifies (hence, greater CO2 emissions), rational plans for forest conservation and reforestation are similarly put in place. More forested areas do not induce significantly greater $\mathrm{CO} 2$ emissions.

\section{IMPACT}

The phenomenon of global warming, as evidenced by several scientific studies, is real and appears to be irreversible. Rise in global temperatures foretells of natural disasters e.g cyclones, hurricanes, typhoons, floods, volcanic eruptions, earthquakes and tsunamis, which nations all over the world are experiencing. Table 2 illustrates the dire consequences of man's unfettered $\mathrm{CO} 2$ emission. Countries belonging to higher and very high HDI registered a total of over 11 deaths per million people (i.e around 110,000 deaths per year) compared to 13 deaths per million (i.e around 130,000 deaths per year).

Over a ten-year period, since the phenomenon of natural disasters have become more frequent, the low and the medium HDI countries suffered a loss of no less than 1.3 million lives. This staggering revelation illustrates that climate change-induced disasters cost the lives of men and women for exceeding any of the known plagues on earth; exceeding even the infamous Bubonic plague in the 1800's. What is ever more dismal is the prospect of continuing such scourge well into the first half of the 21st century.

\section{ETHICAL ISSUES}

Climate and environment ethics issues have surfed of late. More than $80 \%$ of the $\mathrm{CO} 2$ emissions emanate from highly to very highly developed nations, yet the developing and underdeveloped nations equally endure the loss if lives of their citizens due to natural disasters. Can these poorer nations ask for "compensation" from the world's CO2 polluters? If so, how does one quantify the loss of a single human life?

On the other hand, the more developed nations can equally accuse the less developed nations of wanton destruction of forest areas which is also a primary causative factor in the increased atmospheric CO2 accumulation. Can these nations rightly ask for compensation, too?

\section{CONCLUSION}

The impact of human exploitative activities on the accelerated $\mathrm{CO} 2$ accumulation in the atmosphere led to natural disasters spawned by rising global temperatures. Loss of lives and deaths from these natural disasters has forced climate and environmental ethics issues to be raised in the global community of nations. 


$\begin{array}{ll}\text { Originality Index: } & 91 \% \\ \text { Similarity Index: } & 9 \% \\ \text { Paper ID: } & 384592027 \\ \text { Grammarly: } & \text { Checked }\end{array}$

\section{REFERENCES}

Intergovernmental Panel on Climate Change (2007). Observed changes in climate and their effects. IPCC Fourth Assessment Report: Climate Change 2007.

Intergovernmental Panel on Climate Change (2012). Managing the risks of extreme events and disasters to advance climate change adaptation. Special report of the IPCC Australia: Cambridge University Press.

Intergovernmental Panel on Climate Change (2009). Towards a Science-based global harmonized carbon price. IPCC Special Report.

Joint Statement of 18 Scientific Associations (2009). Scientific consensus on global warming. Sound Science Initiative. Union of Concerned Scientists.

McGuire, D. (2009). Sensitivity of the carbon cycle in the Arctic to climate change. Ecological Monographs, 79 (4), 523-555.

United Nations Framework Convention on Climate Change (2009). Fact sheet: The need for mitigation. UNFCCC International.

Van Aalst, M. (2006). The impact of climate change on the risk of natural disasters. Disasters 30(1): 5-18. 